and a control treatment group. This will not mask a drug effect in a treatment group but will permit a more precise estimate of the number of patients in whom the symptom is due to a particular drug.

How can the standardization of symptom reporting be achieved? In my opinion the doctor must not ask verbal auestions but should devise a questionnaire which is completed by the patient. He must ensure that the written questions are understood by the patients, that the questions are completed, and that the questionnaire is returned by a high proportion of patients. Similarly, in a non-treated group the repeatability of the answers (positive or negative) should be tested.

Continuing the example above, a selfadministered questionnaire found that $56 \%$ of patients on methyldopa complained of sleepiness $^{3}$ against $31 \%$ in the general population. ${ }^{4}$ By using such questionnaires the results should be reproducible and the side effects of new therapeutic agents (when evaluated by the same techniques) may be referred back to the known and validated control data.-I am, etc.,

\section{J. BULPITT}

Chronic Disease Control Study Unit, London School of Hygiene and Tropical Medicine,

1 Amery. A., et al., British Medical fournal, 1970, 4. 392.

2 Pritchard, B. N. C., et al., British Medical Fournal, 1968, 1, 135 .

Bulpitt, C. J., and Doilery, C. T., British Medical Fournal. 1973, 3. 485. Fournal of C. Dronic Diseases. In press.

SIR,-I would agree with Drs. E. C. Huskisson and J. A. Wojtuleuski (29 June, p. 698) that the use of a check list of side effects during clinical trials biases both the observer and the patient. One use of a check list which they do not mention, however, is during the pre-trial assessment of the patients. It has been my custom for some years $^{1}$ to use a check list of common symptoms particularly relating to the gastrointestinal and nervous systems. These are recorded as being present frequently, occasionally, or never. I subseauently use a general question such as "Have the tablets upcet you in any way?" and during the final analvsis relate the answers to the pre-trial check list. This is of particular importance in trials in rheumatoid arthritis, where a period on placebo therapy may be considered unethical $^{2}$ so that the comparicons are between two active treatments with no untreated period available for enumeration of "placebo" side effects.-I am, etc.,

IAN HASLOCK

Rheumatology Unit,

Middilechrough General Hospital,

1 Haslock, D. I., Nicholson, P. A., and Wright, V., Clinical Trials fournal. 1971, 8, 43.

1973, 12, Suppl., p. 54.

\section{Vitamin $\mathbf{E}$ in Thalassaemia}

SIR,-Your excellent leading article (22 June, p. 625) directs attention to vitamin $E$, this time as a possible aetiological factor in thalassaemia and other haemolytic states.
Since there are few drugs for which more extravagant claims have been made on flimsier grounds may we amplify some of your comments?

There is no doubt that vitamin $\mathrm{E}$ is a powerful antioxidant in vitro. There is no doubt that the susceptibility of red blood cells to autoxidation is much increased in thalassaemia major and in many other haemolytic states. It is uncertain whether in thalassaemia this is a cause or a consequence of the red cell abnormality. It is plausible but almost certainly untrue that it is in any way related to vitamin $\mathrm{E}$ deficiency. We have treated a number of children with thalassaemia with large doses of vitamin $E$ for periods up to a year. We hope eventually to publish our findings in detail but our provisional conclusions can be briefly stated. It is comparatively simple in this condition to raise serum vitamin $E$ levels to normal by oral medication. It is possible to reduce red cell malonyldialdehyde (MDA) (that is, the in-vitro susceptibility of the cells to autoxidation) to near normal. There is little to suggest that either change has any effect on the haemoglobin pattern or on blood transfusion requirements.

This is not perhaps altogether surprising in the light of recent experimental work. It has long been known that plasma is a powerful antioxidant, and its antioxidant potency can be measured. ${ }^{1-4}$ Fractionation has shown that vitamin $\mathrm{E}$ contributes only marginally to this activity, which is largely a function of two protein fractions. One fraction contains caeruloplarmin, and its mode of action is still uncertain. The second is transferrin, and its antioxidant potency is almost certainly a direct expression of its ironbinding capacity. The key role of iron and of iron binding in lipid autoxidation and antioxidant protection respectively points back to vitamin $\mathrm{E}$ as a possible diagnostic tool. Though, in our experience, the serum level of the vitamin bears no relation to the severity of the haemolysis it does seem to

\section{Community Medicine-a Disclaimer}

SIR,-No doctor acquainted with the starved resources of so many departments of an average district general ho'pital can fail to sympathize with the cry from the heart of "Consultant Radiologist" exclaimed in his Personal View (6 July, p. 38)

What worries me is that his justifiable frustration is laid at the door of community medicine, particularly at this very time when its practitioners are engaged upon the task of endeavouring to demonstrate the true potential of injecting the preventive medicine concept into the whole of the Health Service and of strengthening the resources of the primary medical care teams-currently no less starved than the hospitals - to the better fulfilment of that greater part of medical care which will always fall to be undertaken outside the hospitals.

There are D.H.S.S. circulars which define subtle differences between the work of community physicians and specialists in community medicine, but the fact is that the term "specialist in community medicine" is a generic one, which for reasons of career and training embraces those medical administrators on the staff of regional health authorities who have to continue the un- correlate with the severity of the iron overcoading.

Before discounting vitamin $\mathrm{E}$ as an aetiological factor in thalassaemia we would make two provisos. Firstly, though the increased susceptibility of thalassaemic red cells to autoxidation appears to be the result rather than the cause of the red cell abnormality this is not necessarily true of other haemolytic states. In particular the haemolytic thrombocytopenic syndrome of premature infants described by Oski and Barness ${ }^{5}$ and others almost certainly reflects oxidative damage. (It is also the only syndrome in man which can be attributed with reasonable certainty to vitamin $\mathrm{E}$ deficiency.) Secondly, the fact that vitamin $\mathrm{E}$ deficiency probably plays no causative role in thalassaemia does not mean that, given in pharmacological doses, the vitamin could have no beneficial action. In fact circumstantial and still very incomplete evidence suggests that it might mitigate the effects of iron overloading. The difficulty is that thalassaemia is an extremely heterogeneous disease and iron toxicity is particularly difficult to assess. One is, moreover, dealing with a drug which is being currently promoted for conditions ranging from varicose ulcers through loss of sexual vigour to cancer and old age. The answer clearly requires a carefully controlled-that is, long-term-and properly co-ordinated clinical or laboratory trial or both.-We are, etc.

C. B. MODELL J. STOCKS T. L. DORMANDY

Department of Chemical Pathology,

Whittington Hospital,

Barber, A. A., Archives of Biochemistry and Biobhysics, 1961, 92, 38.

Vidláková, M. et al., Clinica Chimica Acta, 1972 36. 61 .

Storks, J., et al., Clinical Science and Molecular

Medicine, 1974, 47. In press.

tocks. J., et al., Clinical Science and Molecular Medicine, 1947, 47. In press.
Oski, F.

Pediatrics, 1967, 70, 211.

enviable task, formerly undertaken by senior medical officers on the staff of S.A.M.O.s, of dividing up the regional cake of medical manpower and resources between the understandable but currently unattainable desires of the clinical consultants.

Such work, albeit necessary, is scarcely representative of the essence of the emerging specialty of community medicine, which requires such careful nurture during its infancy. It is in no way to disown our hardpressed colleagues holding such appointments to suggest to regional medical officers that the official description "specialist in community medicine" be tucked away in the personal files and that some more specifically descriptive title be adopted for day-to-day use.

Finally, one cannot let pass without disillusion "Consultant Radiologist's" vision of the specialist in community medicine enthroned at the apex of his vast managerial pyramid. Nothing could be further from the truth. Former medical officers of health who had built up carefully trained teams of medical and administrative staff, capable of fulfilling necessary services for the community, now find themselves naked, bereft, 